\title{
A NUMERICAL METHOD TO DETERMINE PHYSICAL SOURCE PARAMETERS FROM FREE OSCILLATION DATA
}

\author{
JORGE A. MENDIGUREN
}

\begin{abstract}
A method to determine physical source parameters using free oscillation data is presented. It is assumed that the geometry of the source is known, e.g. from $P$ wave data. The source is assumed to propagate in the horizontal direction, while unknown parameters to be determined are the azimuth and velocity of propagation, the distance over which the seismic source propagated and the source intensity as a function of propagation distance.

The method consists in the systematic search for the set of source parameters rendering phase corrections which maximize the spectral peak amplitudes within the excitation criterion scheme.

If there is no precursive motion, the average dislocation time function can be determined from the spectrum of the seismic moment and the space source intensity. The source intensity as a function of instantaneous source location is found independently of the $P$ wave origin time and source dislocation time furiction. The method does not require to correct the data for attenuation.
\end{abstract}

RESUMO Este trabalho apresenta um método para determinar parâmetros de fontes sísmicas, usando dados de oscilações livres da Terra. Supõe-se que a fonte se propàga em direção horizontal. Os parâmetros a serem determinados são o azimute, a velocidade de propagação, a distância de propagação da fonte e a intensidade da fonte em função da distância de propagação.

O método consiste na busca sistemática daquele conjunto de parâmetros da fonte, com correspondentes correções de fase que maximizam a amplitude dos picos do espectro quando se utiliza o critério da excitação.

No caso de não haver movimento precursivo, a amplitude média de ruptura, em função do tempo, pode ser determinada a partir do espectro do momento sísmico e da intensidade da fonte. A intensidade da fonte, em função da posição, calcula-se independentemente do tempo origem dado pela onda $\mathrm{P}$ e da amplitude da ruptura em função do tempo. $\mathrm{O}$ métodọ não requer correção para atenuação.

INTRODUCTION Since the 1961 paper by Press, Ben-Menahem and Tokzös, several other studies of source parameters determination. using free oscillation data have been published: Alsop and Brune (1965), Wu (1966), Abe (1970), BenMenahem et al. (1971), Mendiguren (1972), Dziewonski and Gilbert (1974), Kanamori and Anderson (1975), Gilbert and Dziewonski (1975).

With the exceptions of Dziewonski and Gilbert (1974) and Gilbert and Dziewonski (1975), those studies are based on data of spectral peaks clearly identified at single stations. This limited the data to periods longer than 220 seconds or wave lengths above $1200 \mathrm{~km}$, which are unsuitable to study physical parameters of sources of small dimensions (magnitude $\mathrm{m}_{\mathrm{b}}$ smaller than 7 ).

Departamento de Geociências, Universidade de Brasília - 70.000 - Brasília - D.F. - Brasil 
The excitation criterion or stacking technique (Mendiguren 1972, 1973) makes possible to isolate spectral peaks at periods shorter than 100 seconds, and potentially this short period oscillation could be used to derive the physical source parameters over a wider range of source dimensions.

This paper presents a method based on the stacking technique to derive the source parameters from free oscillation data.

EFFECT OF SOURCE PROPAGATION ON THE AMPLITUDE AND PHASE OF SPECTRAL PEAKS A component of displacement corresponding to a given mode of oscillation, say the spheroidal mode of radial order $\ell$ and colatitudinal order $n_{l} S_{\mathrm{n}}$, excited by a double couple point source and having a step function as source time function may be expressed as follows (Saito, 1967; Singh and Ben Menahem, 1969a, b; Gilbert, 1970).

$$
U^{\prime}(\theta, \phi, t)=\sum_{\mathrm{m}=0}^{2} M_{\mathrm{m}} P_{\mathrm{n}}^{\mathrm{m}}(\cos \theta)\left\{\begin{array}{l}
\cos \mathrm{m} \phi \\
\sin
\end{array}\right\} e^{\mathrm{i} \omega_{\ell, \mathrm{n}^{\mathrm{t}}}}
$$

where $M_{\mathrm{m}}=$ coefficient which depends on the mode of oscillation, earth model focal depth and spatial orientation of the double couple.

$P_{\mathrm{n}}^{\mathrm{m}}=$ associated Legendre function.

$\theta, \phi=$ polar spherical coordinates.

$\omega_{\ell, \mathrm{n}}=2 \pi$ eigenfrequency of $S_{\mathrm{n}}$.

$t=$ time measured from the source origin time.

Attenuation effects are considered in other section.

It will be assumed that the source exciting the free oscillations is a double couple point source, with the seismic moment varying as a step function in time, and propagating horizontally with constant velocity from a point $A$ to a point $B$ over a distance $L$, as shown in figure 1 . For simplicity $\mathrm{AB}$ is taken in the direction $\phi=0$.

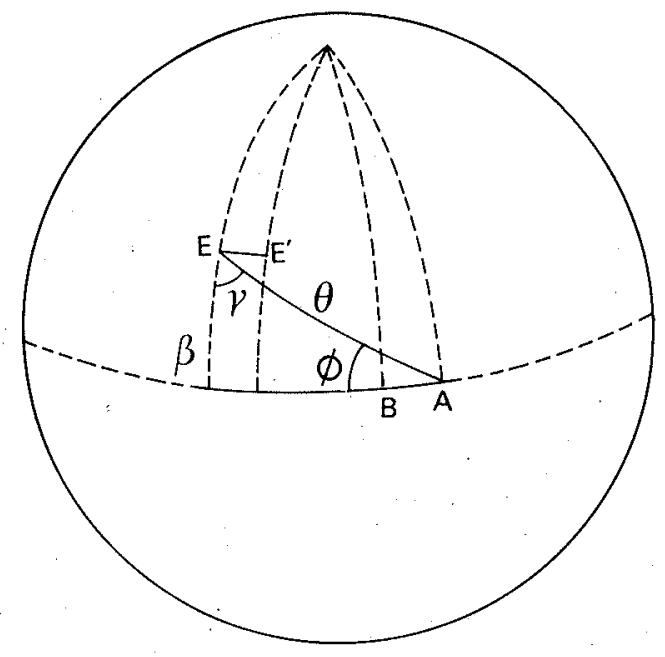

Figure $1-$ The source propagates from $A$ to $B$. $E$ is the observation point 
The amplitude of the oscillation observed at point $\mathrm{E}$ will be given by the integral of the radiation pattern $U^{\prime}(\theta, \phi, t)$ of (1) from $E$ to $E^{\prime}$, along a path of length $L^{\prime}$ parallel to $\mathrm{AB}$, corrected by a proper time delay and weighted by a space source intensity $f(s)$

$$
U(\theta, \phi, t)=L / L^{\prime} \int_{0}^{L} U^{\prime}\left(\theta^{\prime}, \phi^{\prime}, t-s T / L^{\prime}\right) f\left(s L / L^{\prime}\right) d s
$$

where $T$ is the rupture duration time, and $\theta^{\prime}$ and $\phi^{\prime}$ change along the integration path. Press et al. (1961) used a similar expression to study the source mechanism of the 1960 Chilean earthquake.

The source intensity $f(s)$ is the seismic moment spatial density such that its integration over the source propagation distance is

$$
\int_{0}^{L} f(s) d s=M_{0}
$$

where $M$ is the seismic moment as defined by Aki (1966).

As the free oscillation amplitude pattern is a slow changing function of $\phi$ at most changing as $\cos (2 \phi)$ for a double couple point source, while it changes as cos $(n \theta)$ in $\theta$ direction, the $\phi$ dependence of the radiation can be neglected for large $n$ and $\mathrm{E}$ not too close to the epicenter. For example for $\theta=20^{\circ}$ and $n=40$ the amplitude pattern changes at least 7 times faster in $\theta$ than in $\phi$ direction. Then the path $L^{\prime}$ can be replaced approximately by $L^{\prime} \cong L \cos \beta \sin \gamma=L \cos \phi$, and carry the integration (2) along a pure $\theta$ path.

The integration of $P_{\mathrm{n}}^{\mathrm{m}}(\cos \theta)$ involved in (2) can be further simplified for large $n$ and a point not too close to the epicenter by replacing $P_{n}^{m}(\cos \theta)$ for its asymptotic expansion

$$
P_{\mathrm{n}}^{\mathrm{m}}(\cos \theta) \cong(-n)^{\mathrm{m}}\left(\frac{2}{n \pi \sin \theta}\right)^{1 / 2} \cos ((n+1 / 2) \theta-\pi / 4+m \pi / 2)
$$

valid for $n \gg m$ and $\varepsilon<\theta<\pi-\varepsilon$ where $\varepsilon<\pi / 6$, Jahnke and Emde (1945).

Introducing (4) in (1) we get

$$
U(\theta, \phi, t)=N \sin \alpha e^{i \omega_{\ell, \mathrm{n}} \mathrm{t}}
$$

where

$$
\begin{gathered}
N=\left[\frac{2}{n \pi \sin \theta}\left(\left(M_{0}-\left(M_{2 c} \cos 2 \phi+M_{2 \mathrm{~s}} \sin 2 \phi\right) n^{2}\right)^{2}+n^{2}\left(M_{\mathrm{lc}} \cos \phi+M_{1 \mathrm{~s}} \sin \phi\right)^{2}\right)\right]^{1 / 2} \\
\alpha=(n+1 / 2) \theta-\pi / 4+\delta \\
\delta=\tan ^{-1}\left(\frac{M_{0}-\left(M_{2 c} \cos 2 \phi+M_{2 \mathrm{~s}} \sin 2 \phi\right) n^{2}}{\left(M_{1 \mathrm{c}} \cos \phi+M_{\mathrm{ls}} \sin \phi\right) n}\right)
\end{gathered}
$$


$M_{\mathrm{mc}}$ and $M_{\mathrm{ms}}$ are the coefficients of $M_{\mathrm{m}}$ corresponding to the cosine and since terms of $P_{\mathrm{n}}^{\mathrm{m}}(\cos \theta)\left\{\begin{array}{l}\cos m \phi \\ \sin \end{array}\right\}$ in (1)

Introducing (5) in (2) and changing the integration variable

$$
\begin{gathered}
s \text { to } \Omega=(n+1 / 2) s+\alpha_{1} \\
U^{\prime}(\theta, \phi, 0)=\frac{L N}{L^{\prime \prime}} \int_{\alpha_{1}}^{\alpha_{1}+L^{\prime \prime}} \sin \Omega e^{-i \omega^{\prime}\left(\Omega-\alpha_{1}\right)} f\left(\left(\Omega-\alpha_{1}\right) L / L^{\prime \prime}\right) d \Omega
\end{gathered}
$$

where $\omega^{\prime}=\omega_{\ell, \mathrm{n}} T / L^{\prime \prime}, L^{\prime \prime}=L^{\prime}(n+1 / 2), \alpha_{1}$ is the value of $\alpha$ corresponding to $\theta, \phi$ and $\mathrm{t}=0$ is the origin time.

As $N$ is almost constant for $\left|L^{\prime}\right|<<\pi$ it was taken out of the integral (6). The solution of $(6)$ for $f(s)=1$ is

$$
\begin{aligned}
U^{\prime}(\theta, \phi, 0)=\frac{L N}{2 L^{\prime \prime}}\{ & \cos \alpha_{1}\left(-\frac{\cos \left(1-\omega^{\prime}\right) L^{\prime \prime}-1}{\left(1-\omega^{\prime}\right)}-\frac{\cos \left(1+\omega^{\prime}\right) L^{\prime \prime}-1}{\left(1+\omega^{\prime}\right)}\right)+ \\
& \sin \alpha_{1}\left(\frac{\sin \left(1-\omega^{\prime}\right) L^{\prime \prime}}{\left(1-\omega^{\prime}\right)}+\frac{\sin \left(1+\omega^{\prime}\right) L^{\prime \prime}}{\left(1+\omega^{\prime}\right)}\right)- \\
& i\left(\cos \alpha_{1}\left(\frac{\sin \left(1-\omega^{\prime}\right) L^{\prime \prime}}{\left(1-\omega^{\prime}\right)}-\frac{\sin \left(1+\omega^{\prime}\right) L^{\prime \prime}}{\left(1+\omega^{\prime}\right)}\right)+\right. \\
& \left.\left.\sin \alpha_{1}\left(\frac{\cos \left(1-\omega^{\prime}\right) L^{\prime \prime}-1}{\left(1-\omega^{\prime}\right)}-\frac{\cos \left(1+\omega^{\prime}\right) L^{\prime \prime}-1}{\left(1+\omega^{\prime}\right)}\right)\right)\right\}
\end{aligned}
$$

In order to simplify the integration of $(6)$ when $f(s)=1$, the function $f(s)$ was arbitrarily chosen of the form

$$
f(s)=\frac{1-e^{-\left(s /\left(L_{1} R_{1}\right)\right)}}{1-e^{-\left(1 / R_{1}\right)}} \quad \text { for } 0 \leqslant s \leqslant L_{1}
$$

and

$$
f(s)=\frac{1-e^{-\left(1 / R_{2}\right)} e^{\left(\left(s-L_{1}\right) /\left(R_{2}\left(L-L_{1}\right)\right)\right)}}{1-e^{-1 / R_{2}}} \quad \text { for } L_{1}<s \leqslant L
$$


A change in the free parameters $L_{1}, L, R_{1}$ and $R_{2}$ allows a wide variety of shapes to model the source intensity function, as shown in figure $2 . R$ is a free parameter which allows to obtain different shapes for the function $f(s)$.

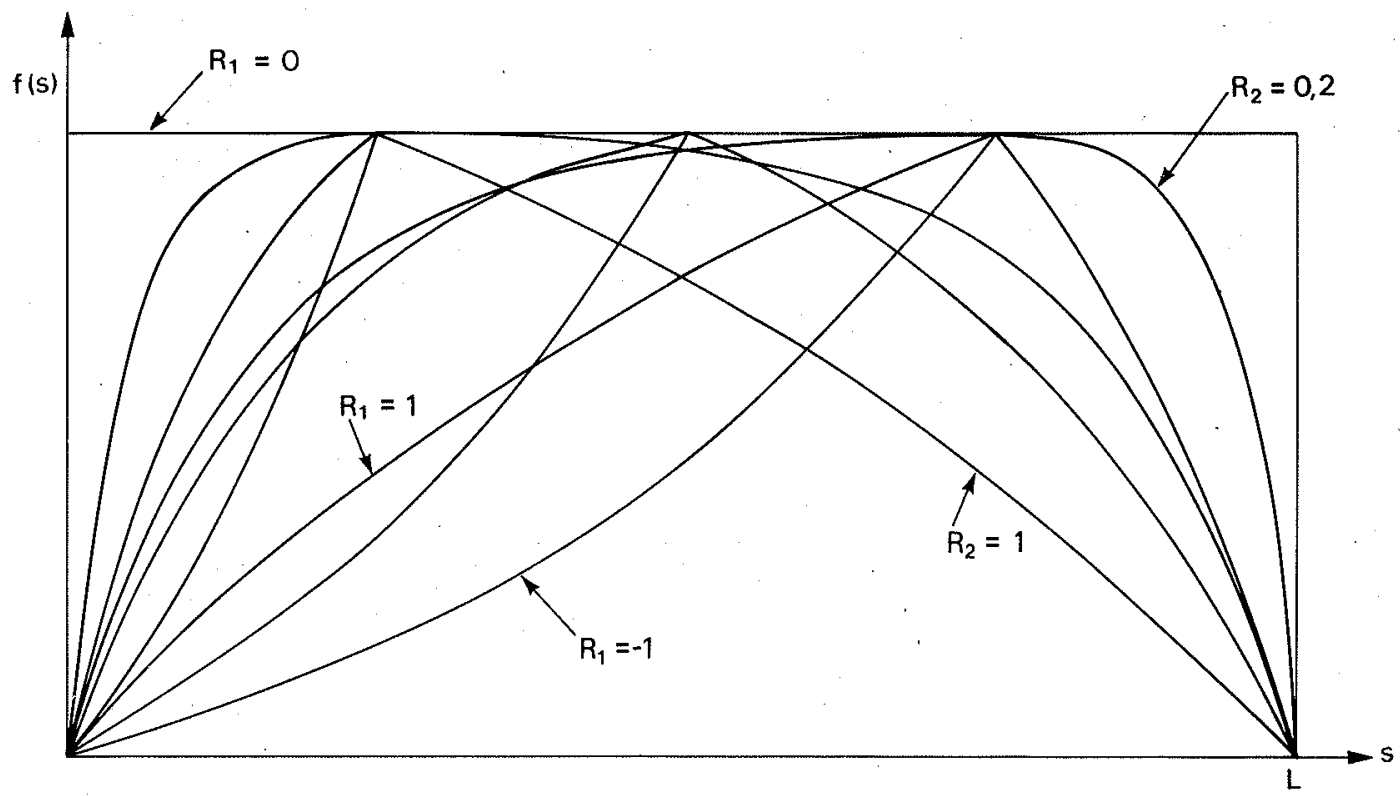

Figure $2-$ Some examples of possible $f(s)$ shapes for $L_{1}$ equal to $0,25,0,50$ and $0,75 L$, and different values of $R_{1}$ and $R_{2}$

Introducing (8) in (6) the result of integration is a sum of 4 terms similar to (7)

$U(\theta, \phi, 0)=\frac{U 7\left(\alpha_{1}, \omega_{1}^{\prime}, L_{1}^{\prime \prime}\right)-U 7\left(\alpha_{1}, \Omega_{1}^{\prime}, L_{1}^{\prime \prime}\right)}{\left(1-e^{\left.-1 / R_{1}\right)}\right.}+$

$\frac{\left(U 7\left(\alpha_{2}, \omega_{2}^{\prime}, L_{2}^{\prime \prime}\right)-U 7 \cdot\left(\alpha_{2}, \Omega_{2}^{\prime}, L_{2}^{\prime \prime}\right) e^{-1 / R_{2}}\right) e^{-\mathrm{i} \omega_{\ell, \mathrm{n}} T_{1}}}{\left(1-e^{-/ R_{2}}\right)}$

where $U 7\left(\alpha_{1}, \omega_{1}^{\prime}, L_{1}^{\prime \prime}\right)$ represents the equation $(7), L^{\prime \prime}=L_{1}^{\prime \prime}+L_{2}^{\prime \prime}, \omega_{1}^{\prime}=\omega_{\ell, \mathrm{n}} T_{1} / L_{1}^{\prime \prime}, \omega_{2}^{\prime}=$ $\omega_{\ell, \mathrm{n}}\left(T-T_{1}\right) / L_{2}^{\prime \prime}, \Omega_{1}^{\prime}=\omega_{1}^{\prime}-i /\left(L_{1}^{\prime \prime} R_{1}\right), \Omega_{2}^{\prime}=\omega_{2}^{\prime}+i /\left(L_{2}^{\prime \prime} R_{2}\right)$ and $\alpha_{2}=\alpha_{1}+L_{1}^{\prime \prime}$.

Expression (9) gives the amplitude and phase of a spectral peak as observed at $\theta, \phi$ for a source propagating horizontally, with an intensity $f(s)$ depending on the instantaneous source location as given by (8).

It applies to a source with a dislocation time function independent of the location of the fault plane and equal to a step function. For any other dislocation time function $d(t)$, (9) should be multiplied times $i \omega D(\omega)$, where $D(\omega)$ is the Fourier transform of $d(t)$.

Note that the rupture velocities $L_{2} /\left(T-T_{1}\right)$ and $L_{1} / T_{1}$ may be different. 
A METHOD TO DERIVE SOURCE PARAMETERS BASED ON THE VECTORIAL SUMMATION OF SPECTRA. The application of the excitation criterion or stacking technique of Mendiguren $(1972,1973)$ to isolate spectral peaks, depends on the possibility of predicting the phase of a peak at different stations for a given reference time, let us say the origin time $t=0$, and therefore to apply a phase correction to the spectra of each station before vectorial summation. For a double couple point source with known spatial orientation the correction to be applied before summation should be simply 0 or $\pi$. For a propagating source the phase correction is given by the phase of $U^{\prime}(\theta, \phi, 0)$ in (9).

Then if we know beforehand the parameters $T, T_{1}, R_{1}, R_{2}, L$ and the double couple orientation, the phase correction for a finite source can be computed using (9). After applying this correction the peaks at all stations for a given mode will be exactly in phase and the vectorial summation of spectra will render a peak of maximum amplitude. As each mode is treated separately and as the attenuation has only a minor effect on the phase, the method does not require correction for attenuation.

Conversely if the source parameters are not known we may apply phase corrections corresponding to different combinations of source parameters trying to maximize the amplitude of the peaks resulting from summation. This search should lead to the actual source parameters as that combination rendering the maximum amplitude.

It is important to point out that the source parameters and the shape of the source intensity $f(s)$ obtained by this method do not depend on the assumed form of the dislocation time function or the starting time of rupture. A shift in the assumed origin time will produce a constant phase shift at all stations that will not affect the amplitude of the peaks obtained by vectorial summation. Equation (9) correspond to a step function as dislocation time function. For any other function equation (9) would include a term $e^{-\mathrm{i} \gamma}$, where $\gamma$ is the difference in phase between a step function and the actual dislocation time function. As $\gamma$ is independent of $\theta$ and $\phi$ (the dislocation time function is assumed to be common to all points on the fault), the phase correction applied to compensate for the effect of the dislocation time function will be the same at all stations, and therefore will not affect the amplitude of the peaks resulting from summation.

Then we could assume a step function when searching for the source parameters. In this case the phase of the resulting maximum amplitude peaks will differ from 0 by an amount equal to $\gamma$. Knowing $\gamma$ as a function of frequency it could be used, in principle, to derive the actual dislocation time function. But now an accurate knowledge of the rupture starting time is required.

So far a source propagating horizontally in one direction has been assumed. If the source propagation has a vertical component, then $L$ will correspond to the horizontal projection of the rupture propagation path. In this case the use of (9) implies the assumption that the coefficients $M_{\mathrm{m}}$ in (1) are not depth dependent. This is not rigorously true, but it is a good first approximation for a source with a vertical propagation much smaller than the vertical wavelength of the oscillations. Therefore the method should be more accurate for $S_{0}$ modes than for higher modes which have eigenfunctions changing more rapidly with depth. When data is constrained to oscillations with wavelengths much longer than the source dimensions, attention should also be paid to the radial wavelength in relation to the vertical propagation of the source. 
DETERMINATION OF THE DISLOCATION TIME FUNCTION. Assuming that the dislocation time function $d(t)$ is common to all points on the fault it can be determined as follows.

For a point source the seismic moment as a function of time is given by

$$
m(t)=d(t) * f(t)
$$

and in the frequency domain

$$
M(\omega)=D(\omega) F(\omega)
$$

or

$$
\dot{M}(\omega)=\dot{D}(\omega) F(\omega)
$$

where the upper dot indicates derivative respect of time

For $\omega=0$

$$
\dot{M}(0)=\int_{-\infty}^{\infty} \dot{m}(t) d t=M_{0}
$$

and from (3)

$$
F(0)=\int_{-\infty}^{\infty} f(t) d t=M_{0}
$$

Therefore

$$
\dot{D}(0)=\int_{-\infty}^{\infty} \dot{d}(t) d t=d(\infty)=1
$$

where $\dot{M}$ ans $\dot{D}$ are the Fourier transform of $m$ and $d$ respectively.

Then knowing $M(\omega)$ and $F(\omega)$ we determine $D(\omega)$ from (10) such that $d(\infty)$ $=1 . M(\omega)$ can be measured independently from observations at all frequencies, while $F(\omega)$ is the spectra of $f(t)$ obtained using the method described in the former section. The difference in final dislocation amplitude for different points in the fault is included in the source intensity $f(s)$. While $f(s)$ is determined independently of $d(t)$ and of the rupture starting time, the determination of $D(\omega)$ from $(10)$ requires to assume that the rupture starts at $P$ wave origin time. 
The method presented in this paper has been succesfully used to study the source mechanism of a deep earthquake. The results will be published in the near future.

Acknowledgements The author is indebted to K. Aki for his advice and critical corrections to the manuscript.

This study was partially supported by a grant from Conselho Nacional de Pesquisas dò Brasil.

\section{REFERENCES}

ABE, K., 1970. Determination of Seismic Moment and Energy from the Earth's Free Oscillations. Phys. Earth Planet. Interiors, 4: 49-61.

AKI, K., 1966. Generation and Propagation of G Waves from the Niigata Earthquake of June 16, 1964, Part 2. Estimation of Earthquake Moment, Released Energy, and StreeStrain Drop from the G Waves Spectrum, Bull. Earthq. Res. Inst., 44: 73-88.

ALSOP, L.E. and BRUNE, J.N., 1965. Observations of Free Oscillations Excited by a Deep Earthquake. Jour. Geophys. Res., 70: 6165-6174.

BEN-MENAHEM, A., ROSENMAN, M. and ISRAEL, M., 1971. Source Mechanism of the Alaskan Earthquake of 1964 from Amplitudes of Free Oscillations and Surface Waves. Phys. Earth Planet. Interiors, 5: 1-29.

DZIEWONSKI, A.M. and GILBERT, F., 1974. Temporal Variation of the Seismic Moment Tensor and the Evidence of Precursive Compression for Two Deep Earthquakes, Nature, (247): 185-188.

GILBERT, F, , 1970. Excitation of the Normal Modes of the Earth by Earthquake Source. Geophys. J. Roy. astron. Soc., 22: 223-226.

GILBERT, F. and DZIEWONSKI, A.M., 1975. An Application of Normal Mode Theory to the Retrieval of Structural Parameters and Source Mechanism from Seismic Spectra. Phil. Trans. Roy. Soc. Lon., (278): 187-269.

JAHNKE, E. and EMDE, F., 1945. Tables of Functions. Dover Publications New York, $117 \mathrm{pp}$.

KANAMORI, H. and ANDERSON, D., 1975. Amplitude of the Earth's Free Oscillations and Long Period Characteristics of the Earthquake Source J. Geophys. Res., 80: 1075. 1078.

MENDIGUREN, J.A., 1972. Source Mechanism of a Deep Earthquake From Analysis of World Wide Observations of Free Oscillations. Ph. D. Thesis, Mass. Inst. of Technol., Cambridge, U.S.A.

MENDIGUREN, J.A., 1973. High-Resolution Spectroscopy of the Earth's Free Oscillation, Knowing the Earthquake Source Mechanism. Science, (179): 179-180.

PRESS, F., BEN-MENAHEM, A. and TOKZÖS, N., 1961. Experimental Determination of Earthquake Fault Length and Rupture Velocity. J. Geophys. Res., 66: 3471-3485.

SAITO, M., 1967. Excitation of Free Oscillations and Surface Waves by a Point Source in a Vertically Heterogeneous Earth. J. Geophys. Res., 72: 3689-3699.

SINGH, S.J. and BEN-MENAHEM, A., 1969a. Eigenvibrations of the Earth Excited by Finite Dislocations - I, Toroidal Oscillations. Geophys. J.R. astron. Soc., 17: 151-177.

SINGH, S.J. and BEN-MENAHEM, A., 1969b. Eigenvibrations of the Earth Excited by Finite Dislocations - II, Spheroidal Oscillations. Geophys. J.R. astron. Soc., 17: 333-350.

WU, F.T., 1966. Lower Limit of the Total Energy of Earthquakes and Partitioning of Energy Among Seismic Waves. Ph. D. Thesis, Calif. Inst. of Technol., Pasadena, USA. 